\title{
Mycotoxins from Beehive Pollen Mycoflora
}

\author{
Adriana M. Cirigliano ${ }^{1}$, Maria Alejandra Rodríguez ${ }^{2}$, Alicia M. Godeas ${ }^{2}$, \\ and Gabriela M. Cabrera ${ }^{1 *}$ \\ ${ }^{1}$ Department of Organic Chemistry and UMYMFOR, FCEyN, Universidad de Buenos Aires, \\ Ciudad Universitaria, Pab. II (1428) Buenos Aires, Argentina. \\ ${ }^{2}$ Department of Biodiversity and Experimental Biology, FCEyN, University of Buenos Aires, \\ Ciudad Universitaria, Pab. II (1428) Buenos Aires, Argentina.
}

Authors' contributions

This work was carried out in collaboration between all authors. All authors read and approved the final manuscript.

Original Research Article

Received $28^{\text {th }}$ September 2013

Accepted $25^{\text {th }}$ October 2013

Published $25^{\text {th }}$ February 2014

\section{ABSTRACT}

Aims: The present study was aimed to search for metabolites produced by fungal strains with antifungal activity against phytopathogens.

Study Design: The pollen of four beehives each from two apiaries from two locations in Argentina (Balcarce and Mar del Plata) was studied. Nine bee pollen samples were randomly collected from each beehive.

Place and Duration of Study: Study was undertaken during 2011 on the Organic Chemistry Department and Biodiversity and Experimental Biology Department, School of Exact and Natural Sciences, University of Buenos Aires.

Methodology: All of the 133 isolated strains were tested for antifungal activity. The most bioactive strains, Myrothecium verrucaria, Nigrospora sphaerica and a levuliform mycelia, were selected for the isolation and identification of compounds responsible for the antifungal activity.

Results: Seven mycotoxins, roridin A, verrucarrin A, $\alpha$ - $\beta$-dehydrocurvularin, phomalactones $A, B, C$ and $D$, were identified spectroscopically and were the responsible the antifungal activity.

Conclusion: Mycotoxins were isolated from beehive pollen mycoflora. This is the first report of the production of these mycotoxins, which are not currently targets for the analysis of pollen or honey products. 
Keywords: Beehive pollen; mycotoxins; trichothecenes; antifungal activity; pollen mycoflora.

\section{INTRODUCTION}

Bee pollen consists of plant pollens, the male reproductive cells of flowers collected by the worker bees that are combined with plant nectar and bee saliva. This product contains photochemical that are particularly rich in carotenoids, flavonoids and phytosterols [1], and nutrients including free amino acids, sugars and mineral elements [2]. The beneficial properties of bee pollen transform this commodity into an increasingly regular ingredient of the human diet, leading to a constant increase in its consumption. But this fact also converts it into a suitable source for the growth of a variety of microorganisms. Fungi successfully colonize the terrestrial environment and efficiently utilize solid substrates by growing over their surfaces and penetrating their matrices [3]. For this reason, a search for natural bioactive microbial products of pollen from beehives as a new source for antifungal metabolites was investigated $[4,5,6]$.

\section{MATERIALS AND METHODS}

\subsection{Bee Pollen Sampling}

Pollen samples were taken from beehives in Mar del Plata, Buenos Aires (B apiary, 4 beehives, $\mathrm{N}=36$ ) and Balcarce, Buenos Aires ( $\mathrm{F}$ apiary, 4 beehives, $\mathrm{N}=36$ ). They were collected from pollen traps and stored frozen in sterile glass containers until analysis. Bee pollen samples were then randomly collected divided and distributed aseptically into sterile flasks to form a solid mass.

\subsection{Selection of Fungal Strains}

A dilution method was applied [7] where $0.4 \mathrm{~g}$ aliquots of pollen were placed in $10 \mathrm{ml}$ of sterile water and vortexed for $1 \mathrm{~min}$. One-tenth serial dilutions were made and the samples were vortexed for 30 seconds each time. The $2^{\text {nd }}$ dilutions $(200 \mu \mathrm{l})$ were seeded into Petri dishes containing malt extract agar (15g agar, $20 \mathrm{~g}$ malt extract, $20 \mathrm{~g}$ glucose and $2 \mathrm{~g}$ peptone) with antibiotics $(0.25 \mathrm{~g}$ of streptomycin and $0.125 \mathrm{~g}$ chlortetracycline). The procedure was performed in triplicate and the Petri dishes were incubated in darkness at $25^{\circ} \mathrm{C}$. Colonies developing on the plates were sub cultured for subsequent identification. A total of 78 isolates from the B apiary and 55 from the $F$ apiary were obtained. All the strains were tested for antifungal activity and the most active strains, Myrothecium verrucaria (LM 278), a levuliform mycelia (LM 336) and Nigrospora sphaerica (LM 314) were further analyzed. These strains were classified by M. A. Rodriguez and A. M. Godeas and deposited at the BAFC culture collection (Fungal collection - School of Exact and Natural Sciences, University of Buenos Aires).

\subsection{Culture}

A well-grown agar slant of each fungus was used to inoculate four $250 \mathrm{ml}$ erlenmeyer flasks containing $100 \mathrm{ml}$ of malt extract medium $(30 \mathrm{~g}$ malt extract and $5 \mathrm{~g}$ peptone per liter). The fermentation was carried out at $25^{\circ} \mathrm{C}$ for 15 days (stationary phase) under static conditions. The optimal fermentation and harvest conditions were determined in previous small scale experiments and agreed with previous reports on secondary metabolite production [8]. 


\subsection{Extraction Procedure, Mycotoxin Isolation and Identification}

A liquid-liquid extraction procedure using ethyl acetate resulted in the best recovery for the isolated compounds because allowed the extraction of a higher number of different metabolites. The same procedure was performed for each culture. The fermentation broth was filtered and the filtrate $(400 \mathrm{ml})$ was partitioned three times with $200 \mathrm{ml}$ of ethyl acetate. The crude organic extract was evaporated in vacuo and was subjected to preparative-scale thin-layer chromatography (Merck, silica gel 60F) leading to the isolated compounds. While the crude extract $(50.0 \mathrm{mg})$ of strain $M$. verrucaria yielded two compounds from preparativescale thin-layer chromatography $\left(\mathrm{CH}_{2} \mathrm{Cl}_{2}\right.$ : ethyl acetate, $\left.1: 1\right)$, roridin $\mathrm{A}(1,2.9 \mathrm{mg}, 5.8 \%)$ and verrucarin $A(2,4.9 \mathrm{mg}, 9.8 \%), \alpha$ - $\beta$-dehydrocurvularin $(3,2.0 \mathrm{mg}, 2.5 \%)$ was obtained from the crude organic extract of LM336. The chromatographic separation (ethyl acetate: methanol, 95:5) of the crude organic extract of $N$. sphaerica $(198.1 \mathrm{mg})$ lead to the isolation of phomalactone (4, $10.1 \mathrm{mg}, 5.1 \%)$, 6-(1-propenyl)-3,4,5,6-tetrahydro-5-hydroxy-4H-pyran2-one (5, $2.0 \mathrm{mg}, 1.0 \%), 5$-[1-(1-hydroxibut-2-enyl)]-dihydrofuran-2-one $(6,1.9 \mathrm{mg}, 1.0 \%)$ and 5-[1-(1-hydroxibut-2-enyl)]-furan-2-one (7, $1.0 \mathrm{mg}, 0.5 \%)$.

The isolated mycotoxins were identified spectroscopically by Nuclear Magnetic Resonance (NMR) and Mass Spectrometry. NMR spectra were recorded on a Bruker Avance II operating at $500.13 \mathrm{MHz}$ for ${ }^{1} \mathrm{H}$ and at $125.13 \mathrm{MHz}$ for ${ }^{13} \mathrm{C}$. Electrospray-High accuracy Mass Spectra were measured on a Bruker micrOTOF Q II (Bruker Daltonics, Billerica, MA, USA).

\subsection{Antifungal Activity}

Direct bioautography of thin-layer chromatography was employed as the method for detecting fungitoxic substances [9]. A concentration level of $25 \mu \mathrm{g} / \mathrm{spot}$ of each compound was assayed. The test was performed against Fusarium lateritium (FL), Fusarium virguliforme (FV) and Botrytis cinerea (BC). Benomyl, a systemic benzimidazole fungicide, was used as a test compound. The assay was repeated in triplicate.

\section{RESULTS}

The search for new sources of bioactive metabolites with antifungal activity led to the study of fungal strains isolated from bee pollen. Three strains, Myrothecium verrucaria, a yeast-like mycelia (LM336) and Nigrospora sphaerica, which showed the highest bioactivities, were chosen from a total of 133 isolates from two apiaries located in Mar del Plata and Balcarce, Buenos Aires. After an exhaustive extraction of the $M$. verrucaria culture, a crude organic extract was subjected to a preparative-scale thin-layer chromatography leading to the isolation of the mycotoxins, roridin A (1) and verrucarrin A (2) (Fig.1).

The structures of these compounds were elucidated by 1D and 2D-NMR (COSY, HSQC, HMBC, NOESY) and HR ESIMS. All the spectroscopical data were in agreement with those reported previously [10] (Tables 1 and 3 supplementary material). These compounds are known trichothecenes previously isolated from this species [11,12]. The crude organic extract of LM336 was subjected to a preparative-scale thin-layer chromatography leading to $\alpha$ - $\beta$-dehydrocurvularin (3) (Fig. 1), identified spectroscopically on the basis of $1 \mathrm{D}$ and $2 \mathrm{D}$ NMR and HR ESIMS. All the spectroscopical data were in full agreement with those reported previously [13,14] (Tables 1 and 3 supplementary material). $\alpha$ - $\beta$-dehydrocurvularin, first isolated and identified by Munro et al. [15] and Hyeon et al. [16], is produced by a number of 
fungal species, especially members of the genus Alternaria which are potent plant pathogens $[17,18,14]$. Finally, four compounds were isolated from the preparative-scale thinlayer chromatography of an ethyl acetate extract of $N$. sphaerica: phomalactone (4), 6-(1propenyl)-3,4,5,6-tetrahydro-5-hydroxy-4H-pyran-2-one (5), 5-[1-(1-hydroxibut-2-enyl)]dihydrofuran-2-one (6) and 5-[1-(1-hydroxibut-2-enyl)]-furan-2-one (7) (Fig. 1). The spectroscopical data were in full accordance with those reported previously $[19,20]$ (Tables 2 and 3 supplementary material). In 1969, Evans, et al. [21] first isolated phomalactone and 6 from Nigrospora sp. Afterward, several authors reported the production of phomalactone from different fungal strains such as Phoma spp. [22] and Hirsutella thomponii [23]. Compound 7 was also isolated from Nigrospora saccari [19]. Recently, compound 5 was isolated for the first time as a natural product together with phomalactone from Xylaria spp. [20]. It was notable that most of the isolated compounds were present in the extracts in high concentrations $(0.5-10 \%)$.

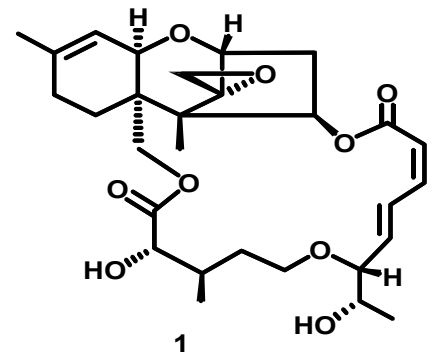

Myrothecium verrucaria

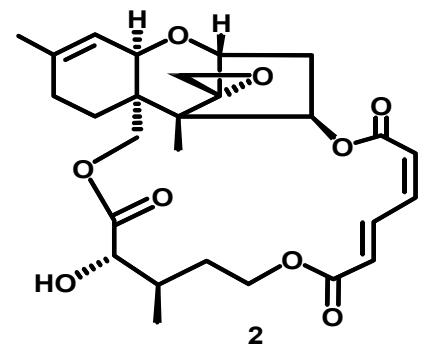

2<smiles>C/C=C/[C@H](O)[C@H]1CCC(=O)O1</smiles>

6<smiles>C/C=C/C(=O)c1c(O)cc(O)cc1CC(=O)OC(C)CCC</smiles>

levuliform mycelia<smiles>CC=CC1OC(=O)C=C[C@@H]1O</smiles>

4<smiles>CC=CC1OC(=O)CC[C@@H]1O</smiles>

5

Nigrospora sphaerica<smiles>C/C=C/[C@H](O)[C@]1(C)C=CC(=O)O1</smiles>

7

Fig. 1. Mycotoxins isolated from beehive's pollen

These compounds were tested for antifungal activity against Fusarium virguliforme, responsible for sudden-death syndrome of soybean and other phytopathogens, Fusarium lateritium and Botrytis cinerea, as the crude extracts of the producing organisms were all active. All the tested compounds have an important activity (inhibition halos from 10 to 20 $\mathrm{mm}$ ) and are responsible for the antifungal activity of the extracts (Table 1).

Table 1. Antifungal activity of isolated compounds 1 to 4 . Diameter of inhibition zone in $\mathrm{mm}(+/-1)$

\begin{tabular}{llll}
\hline Compound & Botrytis cinerea & Fusarium lateritium & Fusarium virguliforme \\
\hline $\mathbf{1}$ & 12 & 10 & 15 \\
$\mathbf{2}$ & 12 & 12 & 17 \\
$\mathbf{3}$ & ND & 10 & 15 \\
$\mathbf{4}$ & ND & 20 & 17 \\
Benomyl & 15 & 25 & 20 \\
\hline
\end{tabular}

N.D: not determined 


\section{DISCUSSION}

The isolated compounds have been previously reported to possess different bioactivities. Roridin A and Verrucarrin A are inhibitors of pollen development in Arabidopsis thaliana [10]. The antifungal activity of roridin A was also reported against Sclerotinia sclerotiorum [24]. $\alpha$ $\beta$-dehydrocurvularin showed sporulation-suppressing activity and also suppressed fungal germination [16] and showed antibiotic activity against Gram-positive and Gram-negative bacteria [25], nematicidal activity [26] and phytotoxicity [14]. Phomalactone is a known antibiotic [14] and an important herbicide [19]. It showed a weak fungicidal activity against Phytophthora infestans [27] and antiplasmodial activity when tested against a chloroquineresistant strain of $P$. falciparum [20]. None of the isolated mycotoxins were previously reported as antifungals against the tested phytopathogen fungal strains. There are only few reports on the isolation of metabolites from fungal strains from beehive pollen mycoflora. Ltenuazonic acid and other tetramic acids and Altertoxin I were isolated from Alternaria brassicicola and Alternaria raphani [5]. Terrestric acid and hydroxyaspergillic acid were isolated from Trichoderma koningii [28]. Other reports on the occurrence of toxigenic fungi in commercial bee pollen focused on the evaluation of the mycobiota occurring in bee pollen and the potential ability of the isolated fungi to produce aflatoxins and ochratoxin A [3]. Recently, aflatoxin B1 production by Aspergillus parasiticus in commercial bee pollen of Greek origin was studied [29]. It is noteworthy that mycotoxins, which are compounds of known toxicity, are not involved in the primary search for pollen or honey product contamination but the results showed in this work would indicate that strains with the ability for a variety of mycotoxin production may be widely present in these products, which are increasingly consumed.

\section{CONCLUSION}

Seven mycotoxins were isolated in high yields $(0.5-10 \%)$ from the crude extracts from the bee pollen: roridin $A$, verrucarrin $A$, $\alpha-\beta$-dehydrocurvularin, phomalactone, 6-(1-propenyl)3,4,5,6-tetrahydro-5-hydroxy-4H-pyran-2-one, 5-[1-(1-hydroxibut-2-enyl)]-dihydrofuran-2-one and 5-[1-(1-hydroxibut-2-enyl)]-furan-2-one. The compounds 1-4 revealed antifungal activity against phytopathogenic fungi.

\section{ACKNOWLEDGEMENTS}

We thank ANPCYT, Universidad de Buenos Aires and CONICET for partial financial support.

\section{COMPETING INTERESTS}

Authors have declared that no competing interests exist.

\section{REFERENCES}

1. Broadhurst CL. Bee products: medicine from the hive. Nutrition Science News. 1999;4:366-368.

2. Serra Bonhevi J, Escola Jorda R. Nutrient composition and microbiological quality of honeybee collected pollen in Spain. Journal of Agricultural and Food Chemistry. 1997;45:725-732. 
3. Gonzalez G, Hinojo MJ, Mateo R, Medina A, Jimenez M. Occurence of mycotoxin producing fungi in bee pollen. International Journal of Food Microbiology. 2005;105:19.

4. Bertinetti BV, Peña NI, Cabrera GM. An antifungal tetrapeptide from the culture of Penicillium canescens. Chemistry \& Biodiversity. 2009;6:1178-1184.

5. Gallardo GL, Peña NI, Chacana P, Terzolo HR, Cabrera GM. L-Tenuazonic acid, a new inhibitor of Paenibacillus larvae. World Journal of Microbiology \& Bio-technology. 2004;20:609-612.

6. Gallardo GL, Peña NI, Cabrera GM. Neric acid derivatives produced by the honey bee fungal entomopathogen Ascosphaera apis. Phytochemistry Letters. 2008;1:155-158.

7. Parkinson D. Filamentous Fungi. In Methods of soil analysis Part 2. Microbiological and Biochemical Properties ed. Weaver RW, Angle S, Bottomley P, Bezdicek D, Smith S, Tabatabai A, Wollum, A. Soil Science Society of America Book Series. Madison, WI. USA. 1994;1121.

8. Calvo AM, Wilson RA, Bok JW, Keller NP. Relationship between secondary metabolism and fungal development. Microbiology and Molecular Biology Reviews. 2002;66,447-459.

9. Homans AL, Fuchs A. Direct bioautography on thin layer chromatograms as a method for detecting fungitoxic substances. Journal of Chromatography A. 1970;51:32-37.

10. Shimada A, Takeuchi S, Kusano M, Fujioka S, Kimura Y, Roridin A, Verrucarin A. Inhibitors of pollen development in Arabidopsis thaliana, produced by Cylindrocarpon sp. Plant Science. 2004;166:1307-1312.

11. Breitenstein W, Tamm C. 13C-NMR-spectroscopy of the trichothecane derivatives verrucarol, verrucarins $A$ and $B$ and roridins $A, D$ and $H$. Helvetica Chimica Acta. 1975;58:1172-1180.

12. Jarvis BB; Stahly GP; Pavanasasivam G, Midiwo, JO, DeSilva T, Holmlund CE, Mazzola EP, Geoghegan Jr RF. Isolation and characterization of the trichoverroids and new roridins and verrucarins. Journal of Organic Chemistry. 1982;47:1117-1124.

13. Ghisalberti EL, Rowland CY. 6-Chlorodehydrocurvularin, a new metabolite from Cochliobolus spicifer. Journal of Natural Products. 1993;56:2175-2177.

14. Vurro M, Evidente A, Andolfi A, Zonno MC, Giordano F, Motta A. Brefeldin A and $\alpha-\beta-$ dehydrocurvularin, two phytotoxins from Alternaria zinniae, a biocontrol agent of Xanthium occidentale. Plant Science. 1998;38:67-79.

15. Munro HD, Musgrave OC, Templeton R. Curvularin. Part V. The compound $\mathrm{C}_{16} \mathrm{H}_{18} \mathrm{O}_{5}$, $\alpha, \beta$-dehydrocurvularin. Journal of Chemical Society (C). 1967;947-948.

16. Hyeon S, Ozaki A, Suzuki A, Tamura $S$. Isolation of $\alpha, \beta$-dehydrocurvularin and $\beta$ dehydrocurvularin from Alternaria tomato as sporulation-supressing factors. Agricultural and Biological Chemistry. 1976;40:1663-1664.

17. Roberson DJ, Strobel G, Strange RN. The identification of a major phytotoxic component from Alternaria macrospora as $\alpha, \beta$-dehydrocurvularin. Journal of Natural Products. 1985;48:139-141.

18. Arai K, Rawlings BJ, Yoshizawa Y, Vederas LC. Biosynthesis of antibiotic A26771B by Penicillium turbatum and dehydrocurvularin by Alternaria cinerariae: comparison of stereochemistry of polyketide and fatty acid enoylthiol ester reductase. Journal of American Chemical Society. 1989;111:3391-3399.

19. Fukushima T, Tanaka M, Gohbara M, Fujimori T. Phytotoxicity of three lactones from Nigrospora Sacchari. Phytochemistry 1998;48:625-630.

20. Jarvis BB, Stahly GP, Pavanasasivam G, Midiwo JO, De-Silva T, Holmund CE, Jimenez-Romero C, Orte-ga-Barria E, Arnold E, Cubilla-Rios L. Activity against Plasmodium falciforum of lactones isolated from the endo-phytic fungus Xylaria sp. Pharmaceutical Biology. 2008;46:1-4. 
21. Evans RH Jr, Ellestad GA, Kunstmann MP. Two new metabolites from an unidentified Nigrospora species. Tetrahedron Letters. 1969;22:1791-1794.

22. Yamamoto I, Suide H, Hemmi T, Yamasno T. Antimicrobial $\alpha-\beta$-unsaturated $\delta$-lactones from molds. Takeda Kenkyusho Ho. 1970;29:1-10.

23. Krasnoff SB, Gupta S. Identification of the antibiotic phomalactone from the entomopathogenic fungus Hirsutella thompsonii var. synnematosa. Journal of Chemical Ecology. 1994;20:293-302.

24. Xie LW, Jiang SM, Zhu HH, Sun W, Ouyang YC, Dai SK, Li X. Potential inhibitors against Sclerotinia sclerotiorum, produced by the fungus Myrothecium sp. as-sociated with the marine sponge Axinella sp. European Journal of Plant Pathology. 2008;122:571-578.

25. Caputo O, Viola F. Isolation $\alpha, \beta$-dehydrocurvularin from Aspergillus aerofulgens. Planta Medica. 1977;31:31-32.

26. Kusano M, Nakagami K, Fujoka S, Kawano T, Shimada A, Kimura Y. $\beta, Y^{-}$ dehydrocurvularin and related compounds as nematicides of Pratylenchus penetrans from the fungus Aspergillus sp. Bioscience, Biotechnology and Biochemistry. 2003;6:1413-1416.

27. Kim JC, Choi GJ, Park JH, Kim HT, Cho KY. Activity against plant pathogenic fungi of phomalactone isolated from Nigrospora sphaerica. Pest Management Science. 2001;57:554-559.

28 Gallardo GL. PhD thesis, Facultad de Ciencias Exactas y Naturales, Universidad de Buenos Aires, 2010.

29. Pitta M, Markaki P. Study of aflatoxin B1 production by Aspergillus parasiticus in bee pollen of Greek origin. Mycotoxin Research. 2010;26:229-234.

(c) 2014 Cirigliano et al.; This is an Open Access article distributed under the terms of the Creative Commons Attribution License (http://creativecommons.org/licenses/by/3.0), which permits unrestricted use, distribution, and reproduction in any medium, provided the original work is properly cited.

Peer-review history:

The peer review history for this paper can be accessed here: http://www.sciencedomain.org/review-history.php?iid=441\&id=22\&aid=3834 